\title{
The effect of buffering on pain and duration of local anesthetic in the face: A double-blind, randomized controlled trial
}

\author{
Oluwatola Afolabi BSc MA MD, Amanda Murphy BSc MD, Bryan Chung MD PhD, Donald H Lalonde MSc MD
}

O Afolabi, A Murphy, B Chung, D Lalonde. The effect of buffering on pain and duration of local anesthetic in the face: A double-blind, randomized controlled trial. Can J Plast Surg 2013;21(4):209. 212.

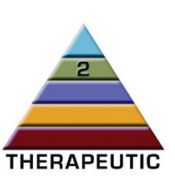

BACKGROUND: The acidity of lidocaine preparations is believed to contribute to the pain of local anesthetic injection.

OBJECTIVE: To investigate the effect of buffering lidocaine on the pain of injection and duration of anesthetic effect.

METHODS: A double-blind, randomized trial involving 44 healthy volunteers was conducted. The upper lip was injected with a solution of: lidocaine 1\% (Xylocaine, AstraZeneca, Canada, Inc) with epinephrine; and lidocaine $1 \%$ with epinephrine and $8.4 \%$ sodium bicarbonate. Volunteers reported pain of injection and duration of anesthetic effect.

RESULTS: Twenty-six participants found the unbuffered solution to be more painful. Fifteen participants found the buffered solution to be more painful; the difference was not statistically significant. Twenty-one volunteers reported duration of anesthetic effect. The buffered solution provided longer anesthetic effect than the unbuffered solution $(\mathrm{P}=0.004)$.

CONCLUSION: Although buffering increased the duration of lidocaine's anesthetic effect in this particular model, a decrease in the pain of the injection was not demonstrated, likely due to limitations of the study.

Key Words: Lidocaine; Local anesthesia; Pain; Sodium bicarbonate

Idocaine, the most common choice for most plastic surgeons, is an Leffective anesthetic with a rapid onset and an excellent safety record. Unfortunately, the administration of lidocaine can be painful.

Many factors influence the pain of injection, including the introduction of the needle, the rate of injection, the pressure from the fluid distention of the tissue (1) and the $\mathrm{pH}$ of the lidocaine solution (2). A weakly basic amide, lidocaine is unstable at its $\mathrm{pH}$ of 7.9 ; therefore, it is prepared in acidic formulations to increase its stability and shelf life. The resultant $\mathrm{pH}$ is typically 4.7 (2). This is well below physiological $\mathrm{pH}$, and the acidity can cause tissue irritation that may be perceived by patients as a stinging or burning pain $(2,3)$.

Several studies have investigated the possibility of reducing pain by buffering lidocaine to reduce its acidity. Sodium bicarbonate is a widely used and safe alkalizer that is metabolized by the kidney. Currently, both buffered lidocaine and unbuffered lidocaine are considered to be standards of care for local anesthesia, with approximately $53 \%$ of emergency physicians routinely adding sodium bicarbonate to lidocaine (4). While studies investigating the effect of buffering in various anatomical sites have been performed, a review of the literature reveals a dearth of research on buffered lidocaine for facial surgery - the most common location for plastic surgery procedures.

The face is a unique area, with several anatomical subunits of highly sensitive specialized tissue, making it possibly different from other regions of the body. It is, therefore, important that local anesthesia for the face be specifically studied. The present study examined the effect of buffered lidocaine on pain sensation in the upper lip. It also investigated the effect of buffering on the duration of anesthetic effect.

\section{L'effet du tamponnage sur la douleur et la durée d'un anesthésique local dans le visage : un essai aléatoire et contrôlé à double insu}

HISTORIQUE : On pense que l'acidité des préparations de lidocaïne contribue à la douleur de l'injection d'un anesthésique local.

OBJECTIF : Examiner l'effet de la lidocaïne tamponnée sur la douleur de l'injection et la durée de l'effet anesthésique.

MÉTHODOLOGIE : Les chercheurs ont mené une étude aléatoire à double insu auprès de 44 volontaires en bonne santé. Ceux-ci se sont fait injecter dans la lèvre supérieure une solution de lidocaïne $1 \%$ (Xylocaine, AstraZeneca Canada, Inc.) associée à de l'épinéphrine, de même qu'une solution de lidocaïne $1 \%$ associée à de l'épinéphrine et à du bicarbonate de sodium $8,4 \%$. Les volontaires ont rendu compte de la douleur de l'injection et de la durée de l'effet anesthésique.

RÉSULTATS : Vingt-six participants ont trouvé la solution non tamponnée plus douloureuse, tandis que 15 participants ont trouvé la solution tamponnée plus douloureuse. La différence n'était pas statistiquement significative. Vingt et un volontaires ont précisé la durée de l'effet anesthésique. La solution tamponnée procurait un effet anesthésique plus long que la solution non tamponnée $(\mathrm{P}=0,004)$.

CONCLUSION : Même si le tamponnage prolongeait l'effet anesthésique de la lidocaïne dans ce modèle, il ne s'associait pas à une diminution de la douleur de l'injection, probablement à cause des limites de l'étude.

\section{METHODS}

After obtaining Research Ethics Board approval from the Saint John Regional Hospital (Saint John, New Brunswick), adult health care workers were recruited as volunteers. Volunteers were excluded from the study if pregnant, or there was a history of surgery or trauma to the face, renal disease, true allergy or sensitivity to local anesthesia. Informed consent was obtained.

Subjects were randomly allocated via a block-randomized sequence. The sequence was generated by a coinvestigator not involved in the injections. The maximum block size was 12 . Both the side of the face to be injected first as well as the order of buffered versus unbuffered solutions to be injected first were randomized. Sequence concealment was achieved using opaque, sealed envelopes. Both injector and subject were blinded to the nature of the solutions; one coinvestigator drew up the solutions and provided them to another coinvestigator to be injected.

The primary outcome of the present study was pain reduction as rated by a single question, "Which injection hurt the most?". Based on prerecruitment sample size and power calculations, 43 participants were set as the target.

A 10:1 mixture of 1\% lidocaine (Xylocaine, AstraZeneca Canada, Inc) with 1:100,000 epinephrine and $8.4 \%$ sodium bicarbonate was the experimental solution (Figure 1). This combination has been shown to raise the $\mathrm{pH}$ of lidocaine to physiological $\mathrm{pH}$ (2). Xylocaine $1 \%$ with 1:100,000 epinephrine without sodium bicarbonate was used as a control solution. Solutions were used within $1 \mathrm{~h}$ of preparation.

The injection site was in the upper lip mid-way between the lip border and the lateral alar base (Figure 2). A 30 -gauge needle on a $3 \mathrm{~mL}$ 

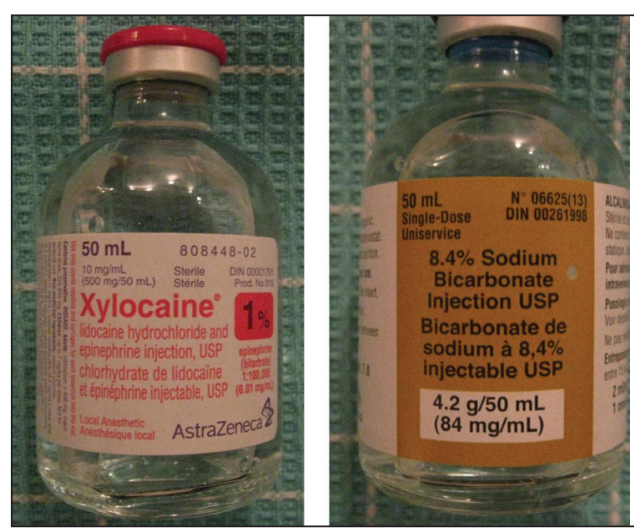

Figure 1) Drugs that were used: $1 \%$ lidocaine (Xylocaine, AstaZeneca Canada, Inc) 1\% with 1:100,000 epinephrine (left) and 8.4\% sodium bicarbonate (right)

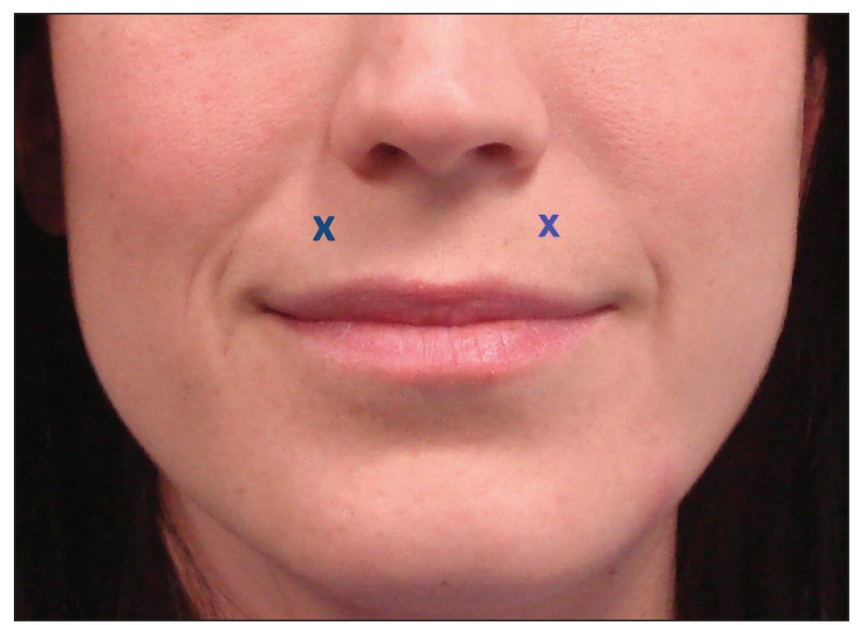

Figure 2) Injection site of each solution in the upper lip is indicated by ' $x$ '

syringe was used to inject volunteers with $1 \mathrm{~mL}$ of test solution on one side and the same volume of control solution on the other. The two injections were both performed within $5 \mathrm{~min}$ of one another in each subject. The subject was then asked to complete a short questionnaire that assessed the pain associated with the injection (Figure 3). Part I of the questionnaire asked volunteers which injection was most painful. Part II asked the participants to rate the pain of each injection on a 10-point visual numerical pain scale (VNS). Part III asked participants how long the anesthetic effect of each injection lasted. Part I and II were submitted within minutes of the injection; part III was returned on a subsequent day.

\section{Statistics}

All data were analyzed in an intention-to-treat manner. A one-sample test of proportions was used to compare the primary outcome, which was the proportion of subjects who found the buffered solution to be less painful to those subjects who did not find the buffered solution less painful (part I). Subjects who found both solutions equally painful were classified as not experiencing pain reduction with buffered lidocaine.

Paired $t$ tests were used to compare both the VNS pain rating scores between buffered and nonbuffered lidocaine as well as duration of effect of each solution. The difference between the buffered and nonbuffered lidocaine VNS scores was also calculated by subtracting the pain VNS of the nonbuffered lidocaine from the pain VNS of the buffered lidocaine. A 95\% CI was calculated around the mean difference in VNS score to provide a measurement of precision; $\mathrm{P}<0.05$ was considered to be statistically significant.

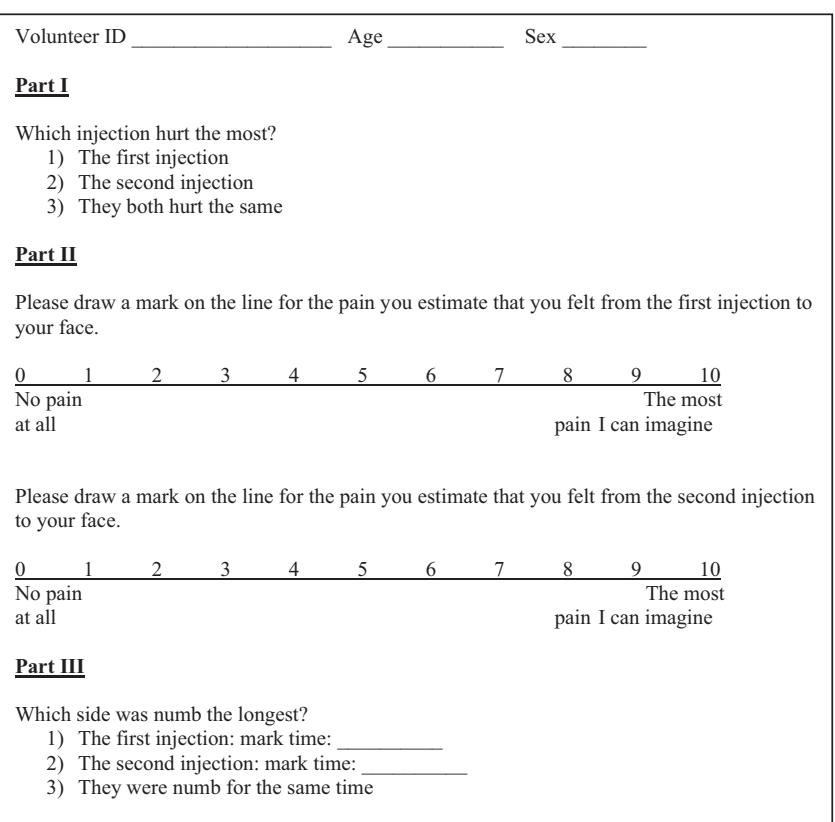

Figure 3) Study questionnaire

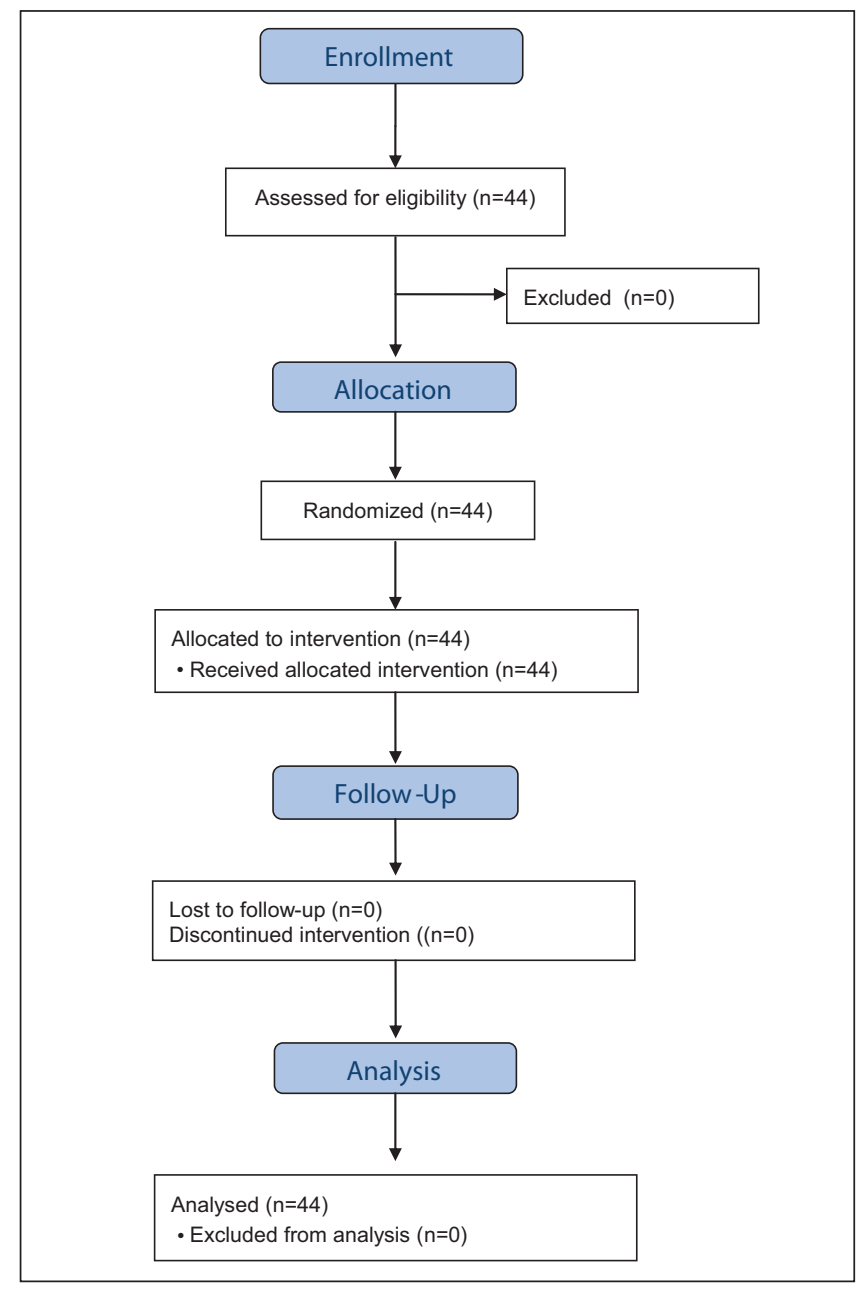

Figure 4) CONSORT flow diagram

\section{RESULTS}

Forty-four subjects were recruited (Figure 4). Twenty-eight (64\%) participants were female and $16(26 \%)$ were male. The mean age was 28.3 years (range 23 to 56 years). 


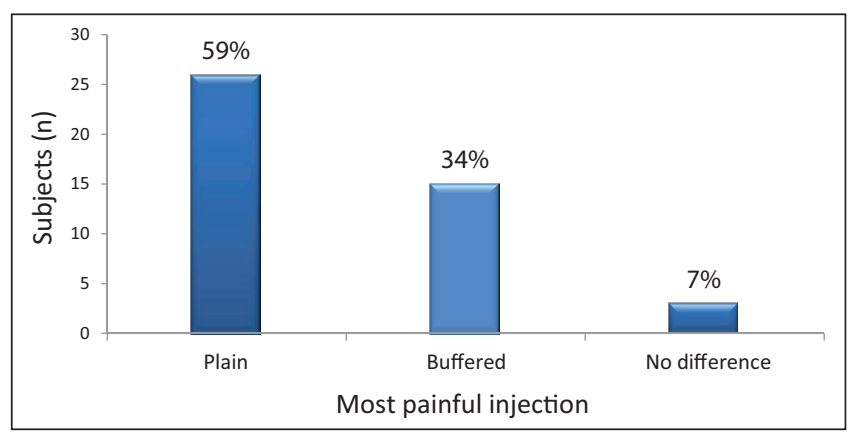

Figure 5) Effect of buffering on pain sensation of lidocaine injection $(P=0.23)$

Twenty-six (59\%) participants found the nonbuffered solution to be more painful. Fifteen (34\%) participants found the buffered solution more painful (Figure 5). Three (7\%) subjects found both injections equally painful. The difference was not statistically significant $(z=-1.2 ; \mathrm{P}=0.23)$.

The mean pain rating for the buffered injection was 4.3 (range 0 to 8 ). The mean pain rating of the plain injection was 5.1 (range of 2 to 9). The mean difference was 0.83 and was not statistically significant $(t=0.23 ; \mathrm{P}=0.82)$. The $95 \% \mathrm{CI}$ around the mean difference in VNS for pain of injection between the buffered and nonbuffered lidocaine was 0.16 to 1.49 .

Twenty-one volunteers (48\% response rate) returned the third part of the questionnaire, which focused on duration of anesthetic effect. The magnitude of effect varied (Figure 6). The mean duration of anesthetic effect for the buffered side was $268.9 \mathrm{~min}$ (range $135 \mathrm{~min}$ to $1282 \mathrm{~min}$ ). The mean duration of the anesthetic effect for the unbuffered side was $219.7 \mathrm{~min}$ (range $0 \mathrm{~min}$ to $1282 \mathrm{~min}$ ). The mean difference was $49.2 \mathrm{~min}$. The buffered solution provided significantly longer anesthetic than did the unbuffered solution $(t=3.27 ; \mathrm{P}=0.004)$.

\section{DISCUSSION}

The present study deviated from most published reports in that it did not demonstrate a statistically different reduction in pain with buffering of local anesthetic, although on average, pain scores were lower for the buffered lidocaine side than the nonbuffered. It is possible that the effect of buffering is overestimated in the face, a particularly sensitive area with numerous nerve endings. Furthermore, it is possible that buffering local anesthetic in the face reduces pain by an order of magnitude that is too small to be detected by our chosen sample size, despite prerecruitment power calculations. Other possible limitations of our study include the fact that the injections were performed by two separate injectors. We did our best to standardize the angle of the needle penetration, the amount of 'wobbling' of the needle in the skin before the needle site was anesthetized (syringe stabilization) and the rate of injection of the anesthetic.

Several factors have been shown to affect the pain of administering local anesthesia. Smaller needle sizes, perpendicular needle angle to the skin, slower speed of injection and warming the solution are all factors that decrease the pain of injection $(1,5-7)$.

A factor that has been investigated by several studies is altering the $\mathrm{pH}$ of lidocaine to be more compatible with physiological $\mathrm{pH}$. Stock preparations of Xylocaine are typically $\mathrm{pH}$ 4.7. This is 1000 times more acidic than physiological $\mathrm{pH}$. The addition of sodium bicarbonate to xylocaine can increase the $\mathrm{pH}$ to 7.4 , which is consistent with physiological pH $(2,3)$.

In a double-blind, cross-over trial study for open carpal tunnel decompression, Vossinakis et al (8) reported a statistically lower rate of pain with buffered lidocaine in a sample size of 21 patients ( 42 hands). Burns et al (9) reported similar findings in their double-blind study. Sixty volunteers were recruited in a cross-over trial: $65 \%$ of participants found the unbuffered solution to be more painful. Firky et al (10)

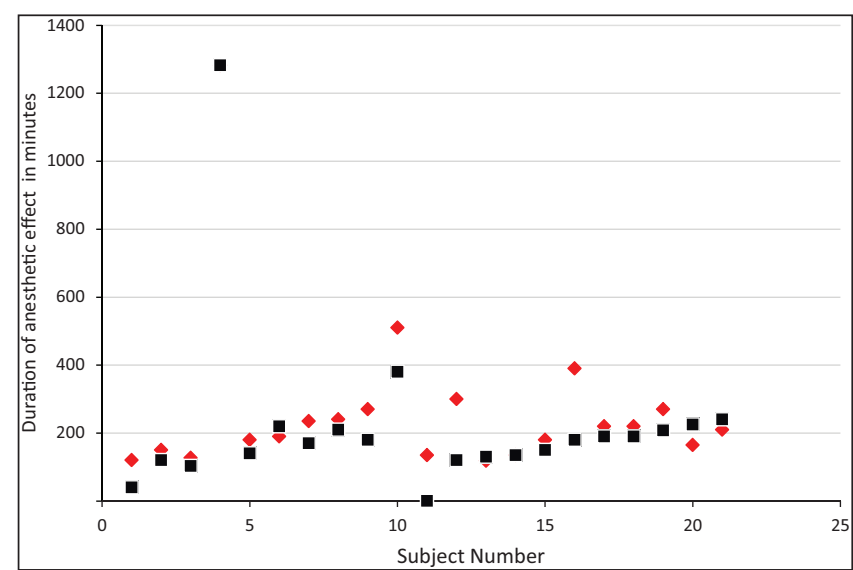

Figure 6) Duration of anesthetic effect for buffered lidocaine (red diamond) and nonbuffered lidocaine (black square) $(P=0.004)$

demonstrated a significant reduction in pain when buffered local anesthetic was used compared with unbuffered lidocaine for multidigital trauma surgery (10). A significant difference was also reported by Fitton et al (11), who used buffered solution for otoplasties.

A recent Cochrane review (12) examined the effect of buffering local anesthetic in 23 studies involving patients (healthy volunteers were excluded). A significant reduction in pain was apparent when lidocaine was buffered.

A second outcome measured in the present study was the duration of anesthetic effect. The anesthetic effect on the side injected with buffered lidocaine lasted longer than on the side injected with plain lidocaine. Few studies have examined the effect of buffering lidocaine on the duration of anesthesia. Christoph et al (13) concluded that buffering did not affect the duration of effect of lidocaine or mepivacaine. A discussion of the pharmacokinetics is beyond the scope of the present article. However, it is plausible that the prolongation of anesthetic with buffering effect may be related to it being a weak base.

Admittedly, our study demonstrated large variation in the duration of effect from subject to subject, with one obvious outlier (Figure 5). These findings are not surprising given the subjective nature of the questionnaire. However, most subjects (17 of 21) reported a longer duration of anesthetic effect with the buffered solution provided, suggesting that this is a consistent finding.

\section{CONCLUSION}

The present study provides level 1 evidence regarding the use of sodium bicarbonate and its effect on the pain of local anesthetic injection in the upper lip. We were not able to demonstrate a difference in the perceived pain of injection by buffering the lidocaine. This may indicate that buffering is less effective in the lip. This result may also be due to some of the limitations of the present study. We did show that buffering increases the duration of lidocaine effect in the face.

\section{REFERENCES}

1. Scarfone RJ, Jasani M, Gracely EJ. Pain of local anesthetics: Rate of administration and buffering. Ann Emerg Med 1998;31:36-40.

2. Momsen OH, Roman CM, Mohammed BA, et al. Neutralization of lidocaine-adrenaline. A simple method for less painful application of local anesthesia. Ugeskr Laeger 2000;162:4391-4.

3. Martin AJ. pH adjustment and discomfort caused by intradermal injection of lignocaine. Anaesthesia 1990;45:975-978.

4. Mader TJ, Playe SJ. Reducing the pain of local anesthetic infiltration: Results of a national clinical practice survey. Am J Emerg Med 1998;16:617.

5. Strazar R, Lalonde D. Five things to know about minimizing injection pain in local anesthesia. CMAJ 2012;184:2015-6. 
6. Hogan ME, vanderVaart S, Perampaladas K, et al. Systematic review and meta-analysis of the effect of warming local anesthetics on injection pain. Ann Emerg Med 2011;58:86-98.

7. Lalonde DH. "Hole-in-one" local anesthesia for wide-awake carpal tunnel surgery. Plast Reconstr Surg 2010;126:1642-4.

8. Vossinakis IC, Stavroulaki P, Paleochorlidis I, et al. Reducing the pain associated with local anesthetic infiltration for open carpal tunnel decompression. J Hand Surg Br 2004;29:399-401.

9. Burns CA, Ferris G, Feng C et al. Decreasing the pain of local anesthesia: A prospective, double-blind comparison of buffered, premixed $1 \%$ lidocaine with epinephrine versus $1 \%$ lidocaine freshly mixed with epinephrine. J Am Acad Dermatol 2006;54:128-31.
10. Fikry $\mathrm{T}$, al Harrar R, Harfaoui A, et al. Local digital anesthesia using lidocaine with or without bicarbonate. A comparative randomized study. Rev Chir Orthop Reparatrice Appar Mot 1998;84:739-42.

11. Fitton $\mathrm{AR}, \mathrm{Ragbir}, \mathrm{M}, \mathrm{Ma} \mathrm{M}$. The use of $\mathrm{pH}$ adjusted lignocaine in controlling operative pain in the day surgery unit: A prospective randomized trial. Br J Plast Surg 1996;49:404-8

12. Cepeda MS, Tzortzopoulou A, Thackrey, et al. Adjusting the $\mathrm{pH}$ of lidocaine for reducing pain on injection. Cochrane Database Syst Rev 2010;(12):CD006581.

13. Christoph RA, Buchanan L, Begalla K, et al. Pain reduction in local anesthetic administration through $\mathrm{pH}$ buffering. Ann Emerg Med 1988;17:117-20. 